\title{
Forecasting National Turnout at British General Elections: Combining Polls and Structural Models
}

\author{
Andreas Erwin Murr
}

Department of Politics and International Studies, University of Warwick, Coventry,

United Kingdom

\section{Simon Munzert}

Hertie School of Governance, Berlin, Germany

Correspondence details:

Andreas Murr (corresponding author)

Department of Politics and International Studies

Social Sciences Building

The University of Warwick

Coventry, CV4 7AL

United Kingdom

Telephone: +44 (0)24 76572959

Email:a.murr@warwick.ac.uk

ORCID: https://orcid.org/0000-0002-9536-0118

Simon Munzert

Hertie School of Governance

Friedrichstr. 180

10117 Berlin

Germany

Email: munzert@hertie-school.org

ORCID: https://orcid.org/0000-0001-5958-9751

Biographical note:

Dr Andreas Murr is Assistant Professor in Quantitative Political Science in the Department of Politics and International Relations and a member of the Warwick QStep Centre.

Dr Simon Munzert is Lecturer in Political Data Science at the Hertie School of Governance and Adjunct Assistant Professor at the University of Maryland and Joint Program of Survey Methodology. 


\title{
Forecasting National Turnout at British General Elections: Combining Polls and Structural Models
}

\begin{abstract}
National election forecasting has become most developed for vote and seat shares as well as winners of elections. These election outcomes are usually forecasted by voter intention polls, structural models, or a combination of the two. For voter turnout, election forecasts come almost exclusively from likelihood-to-vote polls. We develop a structural model of turnout for the British case, and then combine it with likelihood-to-vote polls. We compare poll, structural, and combined forecasts in out-of-sample tests of 18 British general elections from 1951 to 2017. Compared to the polls, the structural model forecasts more accurately, and combining the polls with the structural model increases accuracy even further.
\end{abstract}

Keywords: Bayesian model averaging; forecast combination; fundamentals; polls; turnout.

\section{Introduction}

Election forecasting models are highly developed for two outcomes: votes and seats. ${ }^{1}$ These models are typically tailored to a single country and follow one of three approaches: polls, structural models, or a combination of the two (Lewis-Beck and Stegmaier, 2014).

In addition to votes and seats, another relevant election outcome is turnout. Here, the forecasting is less developed. Most commonly, likelihood-to-vote polls are used as a predictor. The few structural forecasting models of turnout are cross-national in nature (e.g., Evans and Ivaldi, 2012). We know of no structural model of turnout tailored to a single country, and therefore also of no combination of polls and structural models.

\footnotetext{
${ }^{1}$ See, for instance, the recent symposiums for the 2016 US presidential elections (Campbell, 2016) and for 2015 British general election (Fisher and Lewis-Beck, 2016).
} 
Below, we build a structural model of national turnout for British general elections, and then combine it with likelihood-to-vote polls. After reviewing polls as a predictor, we develop the structural model based on the vast explanatory literature of turnout (e.g., Blais, 2000). We then combine the structural model with polls and compare the forecasting accuracy of the three approaches. We find that the combined forecast is best, followed by the structural model and the polls.

\section{Forecasting with likelihood-to-vote polls}

We want to predict the proportion of registered citizens that turn out to vote. ${ }^{2}$ To begin with, we consider likelihood-to-vote polls, for they were used to make the first scientific prediction of turnout (e.g., Katz, 1941; Miller, 1952) and they are very well understood (e.g., Katosh and Traugott, 1981; Bernstein, Chadha and Montjoy, 2001; Selb and Munzert, 2013). In brief, likelihood-to-vote polls provide no explanation of turnout. Also, the early forecasts derived from likelihood-to-vote polls had mixed success, mainly because pollsters and academics where unaware of selection and measurement issues, which typically lead to over-reporting of turnout (Katosh and Traugott, 1981; Bernstein, Chadha and Montjoy, 2001; Selb and Munzert, 2013). For instance, citizens uninterested in politics are less likely to participate in political surveys and to turnout out to vote, resulting in over-representation of voters in realised samples (selection). Similarly, citizens who perceive a social norm of voting are likely to say they are voting

\footnotetext{
${ }^{2}$ We use the turnout figures reported by Mortimor and Blick (2018: 378-382). In a recent
} working paper, Mellon et al. (2018) call attention to errors in turnout measures published for several countries, including the UK. They provide estimates for voter eligible population turnout which are designed to correct for these errors. While the corrected estimates might be the preferable measure, they only available for the last five general elections. Moreover, they happen to be pretty close to the voter turnout figures we use (mean absolute deviation less than one percentage point), which is why we stick to the original (and internally consistent) time series. 
when in fact they are not, resulting in vote over-reporting (measurement).

While over-representation and over-reporting pose a serious problem for individual-level analyses of turnout, it is less serious for aggregate-level predictions as long as there is a strong and systematic relationship between reported likelihood to vote and actual turnout. State-of-the-art election forecasting models prove that recent voting intention polls are an invaluable source to estimate and ultimately forecast trends in voting behaviour (e.g., Linzer, 2013; Wlezien et al., 2013). Hence, it is plausible to expect that likelihood-to-vote polls also provide valuable information for forecasting turnout.

In the British case, likelihood-to-vote polls were collected by Ipsos MORI (2018) since 1979. More specifically, Ipsos MORI collected survey data on the reported likelihood of voting at British general elections. A typical question wording reads "Can you tell me how likely you are to get along to vote in the General Election?". Before the 2001 election, respondents indicated on a 5 -point scale $(1=$ "Certain not to vote"; $5=$ "Certain to vote") their likelihood of voting. Since then, they have been doing so on a 10 point scale ( $1=$ "Absolutely certain not to vote"; 10 = "Absolutely certain to vote"). The polls were conducted with different regularity across elections: in older elections polls were available only a month or two before the election; in more recent elections polls were available for nearly every month. Below, we compare the predictive performance of likelihood-to-vote polls for different response categories (highest, 5 or 10 , vs. highest two, 4-5 or 9-10) at different times (1-2 days vs. 1-2 months vs. before the election).

We predict turnout using the different combinations in every election since 1979. In each election we note the prediction error, i.e. the difference between the actual and predicted turnout. We measure predictive ability with the root mean squared 
prediction error. A smaller root mean squared prediction error indicates better predictive performance. In comparison to the mean absolute prediction error, the measure attaches disproportionately greater weight to predicted values further away from actual ones, i.e. it punishes great misses more severely.

Table 1: Root mean squared prediction error for likelihood-to-vote polls at different times before the election and combining different response categories, 1979-2017.

\begin{tabular}{llc}
\hline Time until election & Response categories & $\begin{array}{c}\text { Root mean squared prediction } \\
\text { error (in \%-points) }\end{array}$ \\
\hline 1-2 days & Highest (5 or 10) & 8.4 \\
& Highest two (4-5 or 9-10) & 18.1 \\
1-2 months & Highest (5 or 10) & 5.8 \\
& Highest two (4-5 or 9-10) & 14.1 \\
\hline
\end{tabular}

Figure 1: British general election turnout predictions using selected forecasting models.

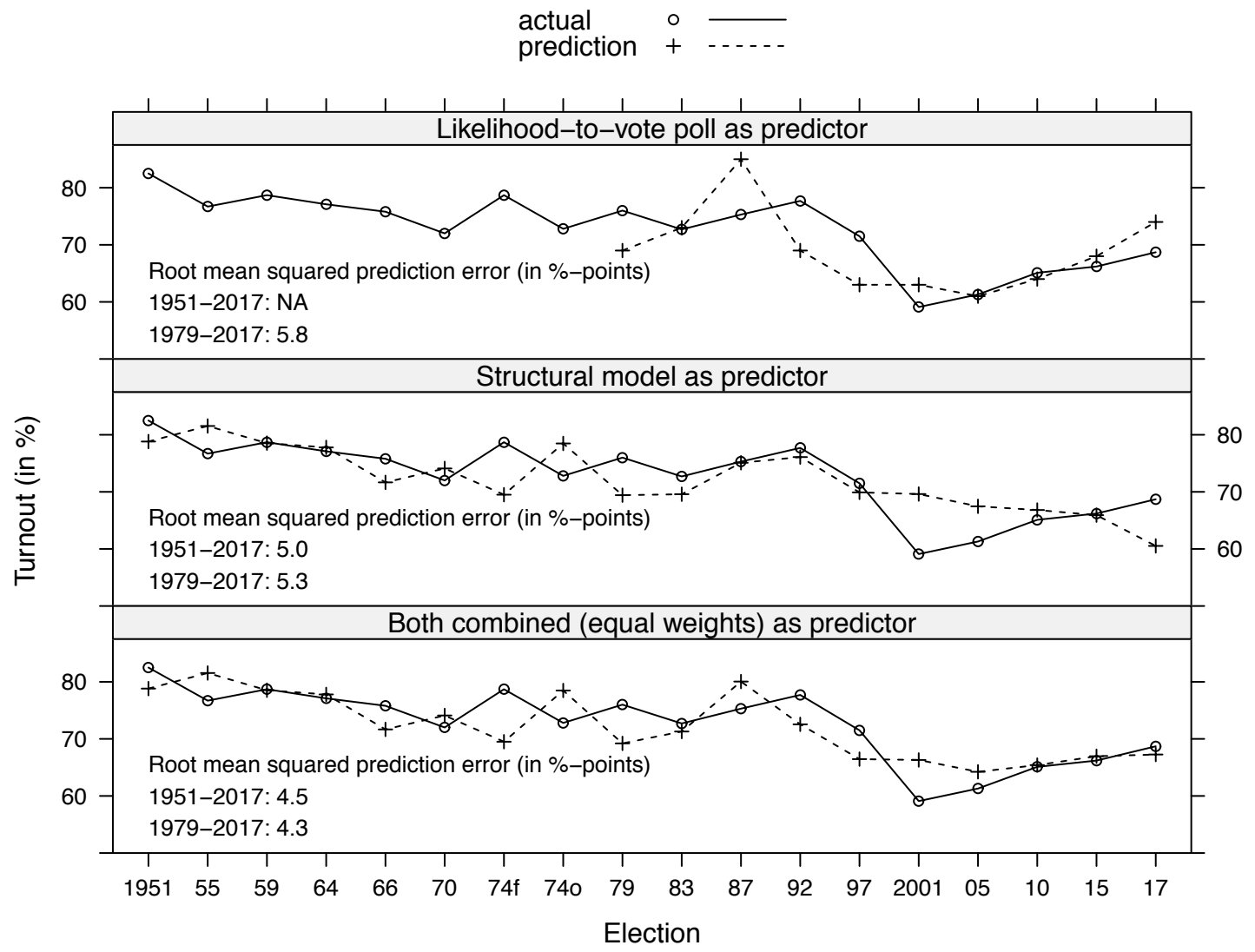


Table 1 presents the root mean squared prediction error from the four versions of likelihood-to-vote polls. The first column contains the time until election and the second the response categories. The last column contains the root mean squared prediction error for the four versions.

Looking at the root mean squared prediction errors, we see that predicting with the highest response category in polls collected 1-2 months before the election is best. It is interesting that polls with more lead time predict better than those with less, holding the response category constant. Apparently, over-reporting or over-representation of voters is increased in last-minute pre-election samples. Hence, to predict turnout with polls, we use the highest category of the 5- or 10-point scale in polls reported one or two months before the election.

Figure 1 (first panel) graphs the actual and predicted turnout of the chosen version of the likelihood-to-vote polls over time. The actual turnout is graphed over 18 elections from 1951 to 2017, the turnout predicted by likelihood-to-vote polls over 10 elections from 1979 to 2017 . When using the highest category only as an indicator for predicted voting, we do not find systematic over-prediction: The polls over-reported four times, under-reported four times, and report "perfectly" twice. On the other hand, an average historical RMSE of almost six percentage points over the past ten elections is underwhelming. Likelihood-to-vote polls alone seem to be a poor basis for turnout forecasting, which is why we explore additional sources of information in the next section. The polls will provide a plausible benchmark against which to evaluate the predictive performance of the structural model, and also a promising candidate for combining their forecasts. 


\section{Building a structural model of turnout}

\subsection{Introducing structural models}

The most common approach to forecasting vote and seat shares is structural. A structural model offers a theory of the election outcomes (e.g., Lewis-Beck and Rice, 1984; Abramowitz, 1988). For instance, some of these models include economic variables such as economic growth, theorising that citizens reward a government if the economy is good, and punish it, if the economy is bad.

We found two recent efforts to forecast levels of turnout, albeit in a crossnational perspective. Bourbeau and Scruggs (2007) use a large cross-national database of over 500 elections to forecast national-level turnout rates in about 100 democratic systems. Evans and Ivaldi (2012) develop a forecasting model for turnout at European Parliament elections in the EU-27 countries. We found no examples of structural models for forecasting turnout in Britain. This paper is the first attempt to build such a structural model.

Our strategy to build a structural model is as follows. First, we searched the literature on turnout for potential predictors that vary across elections, have at least some lead time, and derive from theories. Second, as we are uncertain which of them are good predictors and should be included in the structural model, we use Bayesian model averaging to account for this uncertainty. Finally, as our emphasis is on forecasting, we assess the accuracy of the structural model using out-of-sample forecasts. We also compare the forecasting accuracy of the structural model with the one of likelihood-to-vote polls.

\subsection{Identifying potential predictors}

We identified potential predictors based on three criteria: variation, lead, and theory. 
First, we focus on predictors that vary over time. This focus means that we ignore some important findings of the literature on institutional determinants of turnout. For instance, institutions such as compulsory voting, proportional representation, bicameralism, or the first- or second-order character of the election could affect turnout (see Blais, 2003). However, as the institutions of British general elections stayed constant over the period we are looking at, the evidence from cross-sectional research (e.g., Powell, 1982; Jackman, 1987; Blais and Dobrynzka, 1998) does not inform our selection of potential predictors. For the same reason, we also ignore some major findings of the literature on individual-level determinants of turnout. For instance, the level of education could affect turnout, but levels of education change slowly in the aggregate over time. Hence, this variable and others like it help little to explain election-to-election swings in turnout that we observe.

Second, we focus on potential predictors who could forecast with substantial lead time. Many potential predictors that vary over time exist. For one, increased levels of early voting could be indicative of election-day turnout. For another, rising levels of party polarisation could make the benefits of voting clearer to citizens, and thereby increase the level of turnout. For yet another, Gomez et al. (2007) present evidence for weather effects on levels of turnout at U.S. presidential elections. However, the fact that these predictors are usually available only on or after the day of the election renders them practically useless for forecasting purposes. ${ }^{3}$ For this reason, we refrain from using them at this point.

\footnotetext{
${ }^{3}$ Regarding weather conditions (e.g., precipitation or sunshine duration) we would also conjecture that British voters have long since developed a cheerful apathy towards adverse weather conditions and potential effects could be small in substantive terms and are therefore of limited use for forecasting.
} 
Finally, we focus on predictors that have a good theoretical justification. Focusing on predictors that correlated with turnout in the past, but that have no good theoretical explanation would run the risk of over-fitting the data. To minimise forecasting error, we hence consider only potential predictors grounded in theory.

With the three criteria (variation, lead, and theory) in mind, we reviewed the explanatory literature to identify potential predictors of turnout in Westminster elections. In total we identified twelve potential predictors. For ease of exposition, we have grouped them into themes corresponding to an assumed 'funnel of causality': past turnout, voter intentions, campaign-specific issues, government status, and state of the economy. The themes were sorted roughly in temporal and conceptual distance to turnout in the current election. Table 2 lists the potential predictors and the themes we grouped them into, and indicates their novelty.

Table 2: Potential predictors of turnout grouped into themes of assumed 'funnel of causality'.

I. Past turnout

1. Turnout $_{\mathrm{e}-1}$

2. Linear trend

II. Voter intentions

3. Closeness of election

4. Distance from contention (new)

5. Conservative swing

6. Labour swing

III. Campaign-specific issues

7. Changes in issue agenda (new)

IV. Government status

8. Hung parliament $\mathrm{e}_{\mathrm{e}}$

9. Years since last election

10. Years in office (new)

V. State of the economy

11. Unemployment rate t $_{-1}$

12. GDP growth th

Note: The subscript $\mathrm{t}-1$ denotes the year before the election, $\mathrm{e}-1$ denotes the previous election. 
Past Turnout. An election is not an isolated event, but embedded in a cycle of elections.

Past outcomes are at times good predictors of future outcomes. This also applies to turnout - past levels of turnout can be expected to have a significant impact on future levels of turnout because the composition of the electorate - and its inclination to vote-changes only slowly over time. This is what has been supported by previous empirical work (see Geys, 2006). Consequently, we add lagged turnout to our set of predictors.

Furthermore, there is a broad consensus in the literature that turnout is on the decline in the post-World War II era, in particular since the 1980s (e.g., Blais and Rubenson, 2013; Hooghe and Kern, 2016). While the reasons for this decline are less clear, we try to draw on the overall empirical pattern and employ a linear trend variable that allows us to capture a linear (and likely decreasing) decline in turnout in our sample of elections. ${ }^{4}$

Voter intentions. It is one of the more consistent findings in the literature that the closeness of an election, often measured as the distance in vote shares between the first and the runner-up party, boosts turnout (see Blais, 2000, for an extensive overview). It is a straightforward prediction of rational choice theory that people face higher incentives to vote when the outcome of an election is close, and this is indeed what others have found at the national (e.g., Pattie and Johnston, 2001; Clarke et al., 2006),

\footnotetext{
${ }^{4}$ Without doubt, it is utterly dissatisfying to explain current or future levels of turnout with turnout at past elections or simple time trends, as it adds not much to our understanding of the empirical variability over time, apart from the fact that relative turnout levels tend to change slowly over time. However, it is supposedly a strong predictor and therefore serves as an important baseline variable in any forecasting model of turnout. This is also standard practice in forecasting approaches that target at party vote shares, e.g., in uniform swing models.
} 
the constituency (Denver and Hands, 1974; Franklin, 2004; Loewen and Blais, 2006), and the individual level (Vowles, Katz and Stevens, 2017), although the effects tend to be fairly small..$^{5}$ It is not entirely clear a priori whether voters use knowledge from the previous election or take current polls into consideration to anticipate the closeness in the current election. For the moment, we stick to a measure based on current polls, that is the difference between first and runner-up party in a voter intention poll, which we call closeness. ${ }^{6}$ To that end, we compute the absolute difference between Labour and Conservative shares of voter intentions in the last poll before the election and subtract the result from 100 so that higher values indicate closer elections. ${ }^{7}$

Further, we calculate the difference between second and third party in a voter intention poll. This is a common measure in the strategic voting literature (commonly dubbed distance from contention in this context) to identify incentives for supporters of the party expected to rank third in the district to cast their vote strategically (Niemi, Whitten and Franklin, 1992; Herrmann, Munzert and Selb, 2016). In this case, we argue that while such a setting might positively affect the incentive for a substantive share of voters to cast their vote strategically, it might also lower turnout, especially if the utility

\footnotetext{
${ }^{5}$ Loewen and Blais (2006) report an average decrease in turnout of about one percentage point when the margin of victory increases by ten percentage points.

${ }^{6}$ The voting intention data for the elections between 1950 to 1970 come from King et al. (2001) and for the elections between 1974 and 2017 from Wells (2018).

${ }^{7}$ For variables derived from vote intention polls, we experimented with different lead times, such as the latest poll available one, two, etc. months before the election, as well as the average of all polls available between one and two months, two and three months, etc. before an election. As one would expect, the latest poll available before the election led to the lowest RMSE (see Tables S1 and S2 in the Online Supporting Information for full results), which is why we continue to use the latest poll here. For future applications of the model that require a larger lead time, earlier polls could be used.
} 
potential strategic voters would draw from the success of the second-preferred party or candidate is not large enough.

Finally, a classical hypothesis about the effect of turnout on election outcomes states that electoral results are persistently biased by varying levels of turnout because both the decision to vote and whom to vote for are influenced by the same set of fundamental variables, such education, income, race, and age. The common expectation is that right-wing partisans are more likely to vote, resulting in a pro-conservative bias of voting results (e.g., Burnham, 1965; Radcliff, 1994; Pacek and Radcliff, 1995). While the identification of causal effects of turnout on electoral outcomes bears fundamental problems of endogeneity (see Hansford and Gomez, 2010), one could exploit a possible relationship between both correlates for forecasting purposes without caring too much about the direction of the effect. However, while it is possible to assess vote shares and swings ex post, it is a more difficult endeavour to forecast them in advance of an election. We make use of the latest voter intention polls before the election and the past vote share of parties to measure expected changes in party vote share or swing for the two major parties, i.e. Labour and Conservatives.

Campaign-specific issues. Campaigning mainly serves two purposes: winning new voters and mobilising own partisans. The impact of effort a party puts into a campaign should not only reflect in a higher share of the vote (as demonstrated by, e.g., Pattie, Johnston and Fieldhouse, 1995; Denver and Hands, 1996), but also in increased turnout (Denver and Hands, 1974; Fisher et al., 2015). In fact, turnout is the more intuitive consequence, as two-sided mobilisation efforts might cancel out potential effects on the party share, in particular because parties have been shown to act rational and to focus mobilisation efforts on marginal constituencies (Pattie and Johnston, 1998). Apart from the fact that measuring mobilisation efforts in advance of an election is a difficult 
endeavour, it is unclear under which conditions such efforts (e.g., campaign spending) translate into higher levels of mobilisation.

Instead, we argue that the existence or absence of one or several contentious issues that inflame the public and mobilise party camps could induce variability in turnout. Such issues can be launched by the parties to gain an electoral advantage (in accordance with issue ownership theories; see, e.g., RePass, 1971; Petrocik, 1996) or gain relevance due to external events. We try to tackle the impact of issue-specific mobilisation by measuring the changes in the issue agenda between elections. We measure the issue agenda by responses to Gallup's survey question about the "most important problem" (1946-2001) and to Ipsos-MORI's “most important issue” (19772017) coded by major topics according to the Comparative Agendas Project (John et al., 2013). Considering only the latest polls before elections, we measure the changes in the issue agenda by calculating the maximum absolute difference between the major topics from one election to the next. This is admittedly a crude measure of changes in the issue agenda, but in the absence of other measures we believe it captures the extent to which there are new issues on the agenda that are worth voting for. Our intuitive expectation is that changes in issues that are widely perceived as major problems for a country should push voters to the polling booths.

Government status. Jackman (1987) argues that output from coalitions often involves compromise, which may make voters feel to have less influence on politics. This, in turn, may harm turnout. Consequently, we add an indicator for a hung parliament. Another feature of previous governments that might affect turnout is their tenure. Abramowitz (1988) introduced the idea of "time-for-change" dynamics in U.S. presidential elections, which implied the idea that voters prefer change if the same party stays in power across multiple elections. We extend this argument to turnout. If 
supporters of the opposition party are mobilised to a greater extent than government partisans are demobilised, government tenure might be a driver of turnout. Therefore, we include an indicator of the years in office for the current government.

Similarly, one can speculate about fatiguing effects when the time span between two elections is small. Evans and Ivaldi (2012) follow this rationale and measure proximity of the previous election using the log of days since the last first-order election. We apply a rough indicator that measures the years since the last election.

State of the economy. Powell (1982) and Rosenstone (1982) identified the economic environment as a significant predictor of turnout in cross-national perspective. The contemporary literature, however, reports ambiguous evidence. Effectively, adverse conditions may motivate those who suffer most to go to the urns and vote for reforms, but may also alienate them from the political process. As Blais (2006) summarises, evidence for such effects are very limited, and many studies report a nil finding (e.g., Blais and Dobrzynska, 1998; Kostadinova, 2003; Fornos, Power and Garand, 2004). For the purpose of forecasting, we still include two measures of the economic environment. The first is the unemployment rate one year in advance of the election (see also Evans and Ivaldi, 2012), the second is GDP growth, also measured one year in advance (Bank of England 2017).

To illustrate how these twelve predictors relate to turnout when viewed in isolation, Figure 2 visualises the bivariate relationships. We see that most predictors show no correlation with turnout when considered alone, though some of them do. To give some examples, the first panel shows that turnout at the previous election is positively correlated with current turnout. The second panel points to the historical trend in turnout, showing again that turnout rates have been in a decline for a long time-with 
some exceptions, of course. The fourth panel shows that, counter-intuitively, distance from contention at the national level has a positive correlation with turnout. However, looking at the individual observations, this mostly seems to reflect that Tories and Labour tended to be significantly stronger in the $1950 \mathrm{~s}$ and $60 \mathrm{~s}$, which also happened to be the era of high voter turnout. This points to the need for a multivariate model, to which we now turn.

Figure 2: Bivariate relationships between turnout and predictors, 1951-2017.

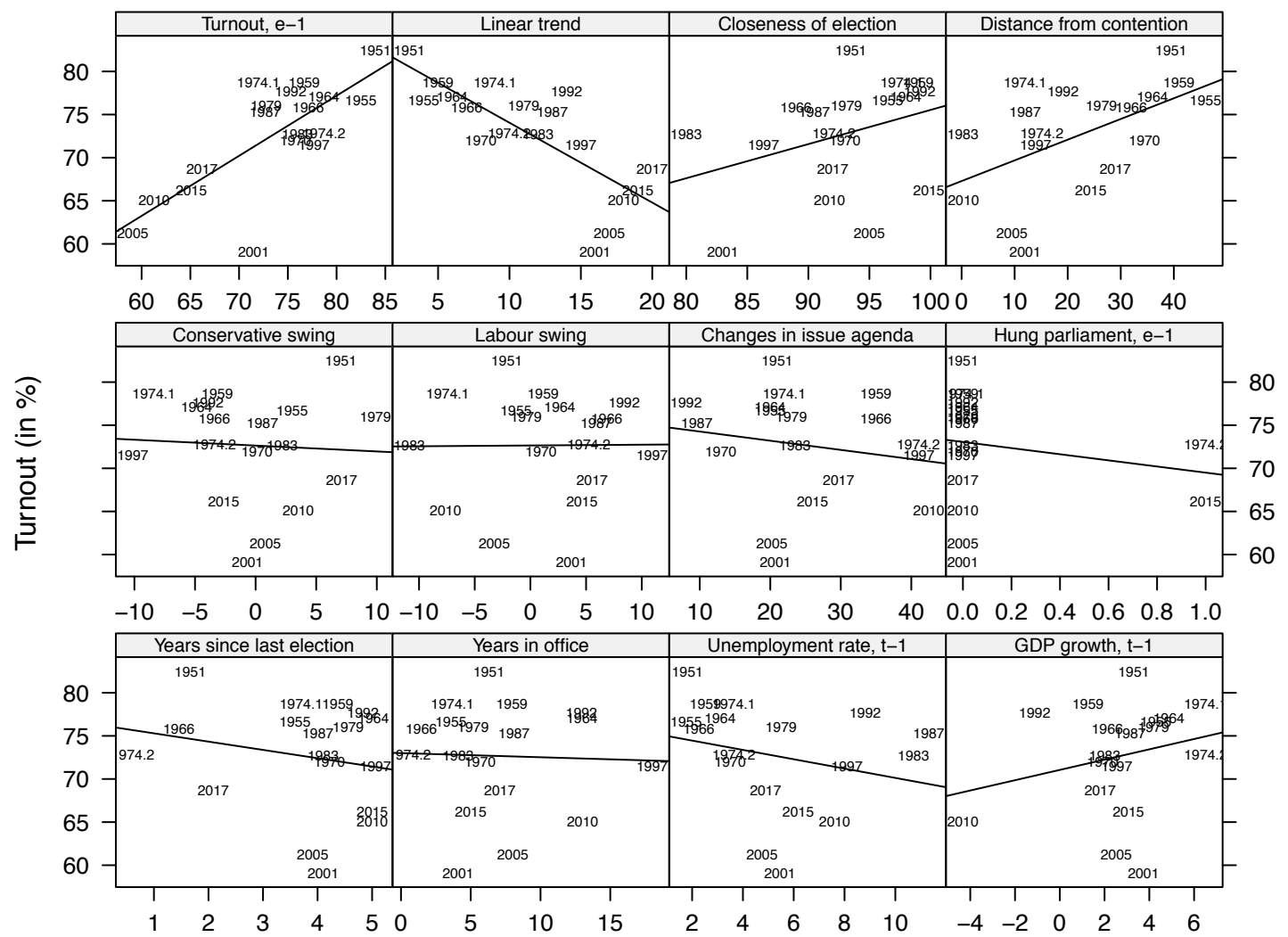

Note: The subscript $\mathrm{t}-1$ denotes the year before the election, $\mathrm{e}-1$ denotes the previous election.

\subsection{Estimating the structural model}

Based on the above literature review, we have identified twelve possible predictors of turnout. As we are unsure about which of them to include in a linear regression model 
of turnout $\mathrm{y}$, we consider $2^{12}=4,096$ models $\mathrm{M}_{1}, \ldots, \mathrm{M}_{4096 .}{ }^{8}$ When estimating the structural model, we use Bayesian model averaging (BMA) to account for uncertainty about this type of model specification (e.g., Leamer, 1978; Bartels, 1997; Hoeting et al. 1999) ${ }^{9}$

BMA includes this uncertainty in inferences about an unknown quantity of interest $\Delta$, such as a population parameter $\theta$ or a future observation $\hat{y}$. The BMA posterior distribution of the quantity of interest is a weighted average of its posterior distribution under each of the models considered. The weight of a model equals the posterior probability that it is true, given that one of the models considered is true.

Bayesian statistics express uncertainty as probability, and make inferences by applying the rules of probability. BMA is Bayesian statistics with model uncertainty. Applying the law of total probability, the BMA posterior distribution of $\Delta$ given data D and possible models $\mathrm{M}_{1}, \ldots, \mathrm{M}_{\mathrm{K}}$ is

$$
p(\Delta \mid D)=\sum_{k=1}^{K} p\left(\Delta \mid D, M_{k}\right) p\left(M_{k} \mid D\right),
$$

where $\mathrm{p}\left(\Delta \mid \mathrm{D}, \mathrm{M}_{\mathrm{k}}\right)$ is the posterior distribution of $\Delta$ given the data $\mathrm{D}$ and model $\mathrm{M}_{\mathrm{k}}$, and $\mathrm{p}\left(\mathrm{M}_{\mathrm{k}} \mid \mathrm{D}\right)$ is the posterior probability that $\mathrm{M}_{\mathrm{k}}$ is the true model given $\mathrm{D}$, assuming that one of the models considered is true. Equation 1 shows that the BMA posterior distribution of $\Delta$ is a weighted average of the posterior distribution of $\Delta$ under each of the models, weighted by their posterior model probabilities.

The posterior model probability $\mathrm{M}_{\mathrm{k}}$ is

$$
p\left(M_{k} \mid D\right)=\frac{p\left(D \mid M_{k}\right) p\left(M_{k}\right)}{\sum_{l=1}^{K} p\left(D \mid M_{l}\right) p\left(M_{l}\right)},
$$

\footnotetext{
${ }^{8}$ This ignores potential transformations or alternative operationalizations of any of the variables, which would effectively boost the number of possible models to infinity.

${ }^{9}$ The exposition in this section is close to Raftery et al. (2005).
} 
where $\mathrm{p}\left(\mathrm{M}_{\mathrm{k}} \mid \mathrm{D}\right)$ is obtained by integrating over the unknown parameters:

$$
p\left(D \mid M_{k}\right)=\int p\left(D \mid \theta_{k}, M_{k}\right) p\left(\theta_{k} \mid M_{k}\right) d \theta_{k}
$$

where $\theta_{k}$ is the parameter of model $M_{k}, p\left(D \mid \theta_{k}, M_{k}\right)$ is the likelihood of $\theta_{k}$ under model $\mathrm{M}_{\mathrm{k}}$, and $\mathrm{p}\left(\theta_{\mathrm{k}} \mid \mathrm{M}_{\mathrm{k}}\right)$ is the prior density of $\theta_{\mathrm{k}}$ under model $\mathrm{M}_{\mathrm{k}}$. As is often the case, we take the prior model probabilities $\mathrm{p}\left(\mathrm{M}_{\mathrm{k}}\right)$ to be equal, so they cancel in Equation 2. (Other formulations would be possible.) In practice, this means that we estimate each model, note its likelihood, and then divide by the sum of all likelihoods to get the posterior model probability.

In addition to forecasting a future observation $\hat{y}$, we also want to learn about model parameters such as the regression coefficient $\beta$. Equation 1 then applies with $\Delta=$ $\beta$. In practice, this means we note the prediction of each model, multiply it by its posterior model probability, and sum over all models. The BMA posterior mean of $\beta$ is the weighted average of the posterior means of $\beta$ under each of the models:

$$
E[\beta \mid D]=\sum_{k=1}^{K} \tilde{\beta}^{(k)} p\left(M_{k} \mid D\right) .
$$

In practice, this means that when estimating a model, we note the coefficient of the variable of interest (setting it to zero if the variable is not in the model), multiply it with the posterior model probability, and then sum the product across models. We implement BMA using the freely available software BMS (Zeugner and Feldkircher, 2015) in R (R Core Team, 2017).

Table 3 shows the summary statistics of the predictors (first three columns) and the BMA estimates of the structural model (last three columns) for the 18 British general elections from 1951 to 2017. The last three columns contain the posterior 
means, standard deviations, and posterior inclusion probabilities $\mathrm{p}(\beta \neq 0 \mid \mathrm{D})$ for the coefficients associated with each predictor.

Table 3: Summary statistics and BMA estimates of structural model based on 18 British general elections (1951-2017).

\begin{tabular}{|c|c|c|c|c|c|c|}
\hline \multirow[t]{2}{*}{ Variable } & \multicolumn{3}{|c|}{ Summary statistics } & \multicolumn{3}{|c|}{ BMA estimates } \\
\hline & Min & $\operatorname{Max}$ & Mean & $\begin{array}{c}\text { Mean } \\
\beta \mid D\end{array}$ & $\begin{array}{l}\text { SD } \\
\beta \mid \mathrm{D}\end{array}$ & $\begin{array}{c}\mathrm{p}(\beta \neq 0 \mid \mathrm{D} \\
)\end{array}$ \\
\hline Closeness of election & 80.00 & 99.88 & 92.75 & 0.54 & 0.32 & 0.87 \\
\hline Unemployment rate $_{t-1}$ & 1.77 & 11.32 & 5.31 & 0.83 & 0.66 & 0.74 \\
\hline Turnout $_{\mathrm{e}-1}$ & 59.10 & 84.00 & 73.51 & 0.43 & 0.37 & 0.69 \\
\hline Linear trend & 3.00 & 20.00 & 11.50 & -0.47 & 0.51 & 0.58 \\
\hline Years since last election & 0.61 & 5.06 & 3.74 & -0.63 & 0.85 & 0.50 \\
\hline Hung parliament $\mathrm{e}_{\mathrm{e}-1}$ & 0.00 & 1.00 & 0.11 & -2.65 & 3.86 & 0.48 \\
\hline Changes in issue agenda & 8.08 & 42.50 & 25.08 & 0.04 & 0.09 & 0.36 \\
\hline Years in office & 0.61 & 18.01 & 7.10 & -0.03 & 0.21 & 0.30 \\
\hline Labour swing & -10.85 & 10.94 & 1.29 & -0.03 & 0.12 & 0.29 \\
\hline Distance from contention & 0.25 & 46.00 & 22.40 & 0.00 & 0.08 & 0.26 \\
\hline Conservative swing & -10.13 & 9.90 & -0.34 & 0.02 & 0.09 & 0.22 \\
\hline GDP growth $_{t-1}$ & -4.33 & 6.52 & 2.69 & 0.01 & 0.20 & 0.22 \\
\hline
\end{tabular}

Note: The subscript $\mathrm{t}-1$ denotes the year before the election, $\mathrm{e}-1$ denotes the previous election.

Interestingly, at least one predictor from each theme is more likely in the model than not, i.e. its posterior inclusion probability is greater than 50\%: lagged turnout and linear trend (past turnout), closeness of elections (voter intention), and unemployment (economy). The only two themes that are not represented are government status (e.g., years since last election have an inclusion probability of 50\%) and campaign-specific issues (changes in issue agenda have a posterior inclusion probability of only $36 \%$ ). Even with these two exceptions, the structural model seems to draw on short-, medium-, and long-term predictors. This broad time horizon should result in good predictive performance. 
Table 4: The ten component models with the highest posterior model probability.

\begin{tabular}{|c|c|c|c|c|c|c|c|c|c|c|}
\hline & \multicolumn{10}{|c|}{ Model } \\
\hline & 1 & 2 & 3 & 4 & 5 & 6 & 7 & 8 & 9 & 10 \\
\hline Closeness of election & $\checkmark$ & $\checkmark$ & $\checkmark$ & $\checkmark$ & $\checkmark$ & $\checkmark$ & $\checkmark$ & $\checkmark$ & $\checkmark$ & $\checkmark$ \\
\hline 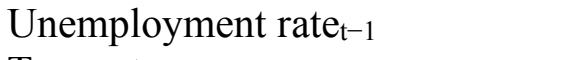 & $\checkmark$ & $\checkmark$ & $\checkmark$ & $\checkmark$ & $\checkmark$ & $\checkmark$ & $\checkmark$ & & $\checkmark$ & $\checkmark$ \\
\hline Turnout $_{\mathrm{e}-1}$ & & $\checkmark$ & & $\checkmark$ & $\checkmark$ & $\checkmark$ & $\checkmark$ & $\checkmark$ & $\checkmark$ & $\checkmark$ \\
\hline Linear trend & $\checkmark$ & & $\checkmark$ & & $\checkmark$ & & $\checkmark$ & & $\checkmark$ & $\checkmark$ \\
\hline Years since last election & $\checkmark$ & & & $\checkmark$ & $\checkmark$ & $\checkmark$ & & & $\checkmark$ & $\checkmark$ \\
\hline Hung parliament $\mathrm{e}_{\mathrm{e}-1}$ & & $\checkmark$ & & $\checkmark$ & $\checkmark$ & $\checkmark$ & & & & $\checkmark$ \\
\hline Changes in issue agenda & & $\checkmark$ & & & & $\checkmark$ & & & & $\checkmark$ \\
\hline Years in office & & $\checkmark$ & & & & $\checkmark$ & & & & \\
\hline Labour swing & & & & $\checkmark$ & & & & & & \\
\hline Distance from contention & & & & & & & & & & \\
\hline Conservative swing & & & & & & & & & & \\
\hline 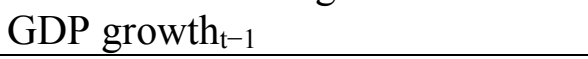 & & & & & & & & & & \\
\hline Posterior model probability & 2 & 2 & 1 & 1 & 1 & 1 & 1 & 1 & 1 & 1 \\
\hline
\end{tabular}

Note: The subscript $\mathrm{t}-1$ denotes the year before the election, $\mathrm{e}-1$ denotes the previous election. The symbol $\checkmark$ denotes that a variable is included in the model.

The results shed light on the role of the past, the current election and government, as well as the economy in shaping turnout. The coefficients suggest that closer elections have higher turnout than landslide elections. Similarly, turnout is higher in elections with a higher compared to a lower unemployment rate. As expected, the turnout rate at the previous election is closely related to turnout at the current one, though the turnout rate is declining over time. Finally, there is some evidence that turnout is lower in elections after a hung parliament.

Table 4 lists the ten component models with the highest posterior probabilities. The component model with the highest posterior probability includes four variables: closeness of the election, unemployment rate, the linear trend, and years in office. Nonetheless, this model represents only $2 \%$ of the total posterior probability, indicating that there is a substantial amount of model uncertainty. This means that even the forecast of the best model has only a weight of 0.02 when averaging across the forecast of all models. Similarly, the top ten models account for only $12 \%$ of the total posterior 
probability. The fact that the posterior probability is very spread among many models suggests the superiority of estimating the structural model with BMA over choosing any single model.

\subsection{Assessing the predictive performance}

We assess the predictive power of the structural model with out-of-sample forecasts based on the data from the 18 elections from 1951 to 2017 . We repeatedly split the data into a training set containing 17 elections and a validation set containing the remaining election. We fit the structural model with BMA to the training set and then make a prediction for the excluded observation.

Figure 1 (second panel) graphs the actual and predicted turnout of the structural model over time. We see that predicted turnout closely follows the actual one most of the time. In many elections such as in 2015 the structural model forecast is nearly "perfect". However, there are some exceptions, most notably the elections in February 1974, 2001, and 2017. Overall, the structural model forecast is the best so far. Its root mean squared predictive error is lower than the one for likelihood-to-vote polls. For elections from 1979 to 2017 , moving from the poll to the structural model forecast reduces the root mean squared predictive error by $(1-5.3 / 5.8=) 10 \%$. Below, we examine whether combining poll and structural model forecasts increases accuracy even further.

\section{Combining poll and structural model forecasts}

Finally, we consider combining the predictions of likelihood-to-vote polls and the structural model as a way to increase accuracy even further. Election forecasters increasingly combine voter intention polls and structural models to predict vote shares (e.g., Linzer, 2013; Erikson and Wlezien, 2013). It is well known that combining 
forecasts often increases accuracy (Bates and Granger, 1969; Clemen, 1989).

What can likelihood-to-vote polls offer to the structural model? Substantively, likelihood-to-vote polls seem to contain information that is not included in the structural model. In the structural model, most of the important variables - unemployment, previous turnout, and trend - capture medium- to long-term dynamics. Only one important structural variable - closeness - captures some short-term dynamics. Hence, likelihood-to-vote polls offer to pick-up short-term shifts in voter mobilisation due to campaign-specific idiosyncrasies.

Statistically, the mean of multiple forecasts has a lower variance than each of its component forecasts, resulting in a lower root mean squared error (assuming unbiased component forecasts with equal variance). Because poll and structural model forecasts show no bias and similar variance, we will combine both with equal weights. In other words, if both forecast components are available, we will take their mean in each election, (forecast Polls + forecast $_{\text {StructuralModel }}$ / 2. If a poll is unavailable, we will use the structural model alone.

Figure 1 (third panel) graphs the actual and predicted turnout after combining likelihood-to-vote polls and the structural models. As expected, the combined forecast is better than its components on average. The benefits of combining forecasts are perhaps best illustrated with the recent 2017 election. Here, the likelihood-to-vote poll overpredicts while the structural model under-predicts by the same amount, leading to a near "perfect" combined forecast. Looking at the root mean squared prediction error for both periods, we see that the combination is the best forecast (RMSE $=4.5$ for the entire period 1951-2017 and 4.3 for the period 1979-2017), followed by the structural model $(\mathrm{RMSE}=5.0$ and 5.3, respectively), and the likelihood-to-vote poll $(\mathrm{RMSE}=\mathrm{NA}$ and 5.8, respectively). For elections from 1979 to 2017, moving from polls or the structural 
model to the combined forecast reduces the root mean squared predictive error by (1 $4.3 / 5.8=) 26 \%$ or by $(1-4.3 / 5.3=) 18 \%$, respectively. As a result, we think that combining likelihood-to-vote polls with the structural model is a promising way to go for forecasting turnout in the future.

\section{Summary and conclusion}

This paper offers a first effort at building a forecasting model of turnout in Britain, considering both likelihood-to-vote polls and a structural model. Our results indicate the relative accuracy of poll, structural model, and combined forecasts.

The most accurate poll forecasts use only the highest category of the reported likelihood of voting, collected 1-2 months before the election. The most accurate polls did not tend to over- or under-predict turnout, but were not very precise, with a historical out-of-sample RMSE of almost six percentage points.

Compared to polls, the structural model forecasted better. The structural model of turnout was based on mainly five predictors: closeness of the election, the unemployment rate, previous turnout, a linear trend, and an indicator of hung parliament. This implies that the economy matters in different ways for forecasting turnout than re-election. Whereas GPD growth forecasts a re-election of the government (e.g., Lewis-Beck, 1988), the unemployment rate seems to forecast a rise in the level of turnout. In general, what predicts turnout seems different from what predicts vote and seat shares or who wins, highlighting the need for developing structural forecasting models of turnout. Still, the structural model was off by an RMSE of more than five percentage points on average.

Overall, the simple mean of poll and structural model forecasts was the most accurate. Polls seem to add campaign-specific information, which the structural model does not capture. By combining both, we were able to reduce the RMSE to about four 
percentage points. This implies that also cross-national turnout forecasting models would gain accuracy by combining their structural models with polls.

Overall, the accuracy of all of our models is far from satisfying. It seems that with the large body of research on turnout at hand and facing a rather unsophisticated quantity of interest, it should be possible to forecast turnout with higher precision. However, previous research has mainly focused on single determinants of turnout in isolation. These approaches run the risk of overfitting the data. Moreover, good insample statistics and low p-values do not imply high predictive ability. If the goal is to predict turnout, one of the challenges is to deal with the practically infinite model space. Selecting only one of them or focusing on a sole predictor, such as likelihood-to-vote polls, both harms out-of-sample forecasting accuracy and leads to an underestimation of forecasting uncertainty. To address these issues, our paper engaged in a Bayesian model averaging approach. Another limitation that is hard to overcome is the small number of past elections to learn from. We hope that our forecasting model of turnout will stimulate more efforts to forecast turnout in Britain as well as in other contexts in the future, ultimately enabling more precise forecasts.

\section{Acknowledgements}

Previous versions of the paper (which were essentially a different paper) were presented at the EPSA Conference 2015 (Vienna) and the ESRA Conference 2015 (Reyklavik) and the MZESSFB Workshop on Political Forecasting (Mannheim). A frozen snapshot of our structural model forecast for the 2017 British general election, which convinced us of the value of combining poll and structural model forecasts, can be found at https//osf.io/d8a39. We thank all panel participants, Stephen Fisher, and Ericka Rascón Ramirez for valuable comments. Furthermore, we are most grateful to Will Jennings for providing us with monthly-level MIP data.

\section{References}

Abramowitz, Alan I. 1988. “An Improved Model for Predicting Presidential Election Outcomes." PS: Political Science and Politics 21(4):843-847. 
Bank of England. 2017. A millennium of macroeconomic data for the UK (Version 3.1).

URL: https://www.bankofengland.co.uk/statistics/research-datasets.

Bartels, Larry M. 1997. "Specification uncertainty and model averaging." American Journal of Political Science 41(2):641-674.

Bates, J.M. and C.W.J. Granger. 1969. “The Combination of Forecasts.” Operational Research Quarterly 20(4):451-468.

Bernstein, Robert, Anita Chadha and Robert Montjoy. 2001. "Overreporting Voting: Why It Happens and Why It Matters." Public Opinion Quarterly 65(1):22-44.

Blais, André. 2000. To Vote Or Not To Vote? The Merits and Limits of Rational Choice. Pittsburgh: University of Pittsburgh Press.

Blais, André. 2006. "What Affects Voter Turnout?” Annual Review of Political Science 9:111-125.

Blais, André and Agnieszka Dobrzynska. 1998. "Turnout in electoral democracies." European Journal of Political Research 33:239-261.

Blais, André and Daniel Rubenson. 2013. "The Source of Turnout Decline." Comparative Political Studies 46(1):95-117.

Bourbeau, James and Lyle Scruggs. 2007. "Modeling and Forecasting Electoral Participation around the World: Voter Turnout in Democratic Regimes, 19722006." Presented at the 2007 Annual Meeting of the American Political Science Association, Chicago, IL August 31, 2007.

Burnham, Walter Dean. 1965. "The Changing Shape of the American Political Universe.” American Political Science Review 59(1):7-28.

Campbell, James E. (ed.). 2016. "Forecasting the 2016 American National Elections." PS: Political Science and Politics 49(4).

Citrin, Jack, Erick Schickler and John Sides. 2003. "What if Everyone Voted? Simulating the Impact of Increased Turnout in Senate Elections.” American Journal of Political Science 47(1):75-90.

Clarke, Harold, Marianne Stewart, David Sanders and Paul Whiteley. 2006. "Taking the Bloom Off New Labour's Rose: Party Choice and Voter Turnout in Britain, 2005.” Journal of Elections, Public Opinion and Parties 16(1):3-36.

Clemen, Robert T. 1989. "Combining forecasts: A review and annotated bibliography." International Journal of Forecasting 5(4):559-583.

Denver, D. and G. Hands. 1996. Constituency campaigning in the 1992 general election: the peculiar case of the Conservatives. In British elections and parties 
yearbook 1996, ed. D. M. Farrell, D. Broughton, D. Denver and J. Fisher. London: Frank Cass pp. 85-105.

Denver, D. T. and H. T. G. Hands. 1974. "Marginality and Turnout in British General Elections.” British Journal of Political Science 4:17-35.

Erikson, Robert S. and Christopher Wlezien. 2014. "Forecasting US Presidential Elections Using Economic and Noneconomic Fundamentals.” PS: Political Science and Politics 47(2):313-316.

Evans, Jocelyn and Gilles Ivaldi. 2012. "Deriving a Forecast Model for European Election Turnout." Political Research Quarterly 65(4):855-867.

Fisher, Justin, Edward Fieldhouse, Ron Johnston, Charles Pattie and David Cutts. 2015. "Is all campaigning equally positive? The impact of district level campaigning on voter turnout at the 2010 British general election." Party Politics.

Fisher, Stephen D. and Michael S. Lewis-Beck (eds.). 2016. "Forecasting the 2015 British General Election." Electoral Studies 41(1).

Fornos, C.A., T.J. Power and J.C. Garand. 2004. "Explaining Voter Turnout in Latin America, 1980 to 2000.” Comparative Political Studies 37(8):909-940.

Franklin, Mark. 2004. Voter Turnout and the Dynamics of Electoral Competition in Established Democracies Since 1945. Cambridge, UK: Cambridge University Press.

Geys, Benny. 2006. "Explaining voter turnout: A review of aggregate-level research." Electoral Studies 25:637-663.

Gomez, Brad T., Thomas G. Hansford and George A. Krause. 2007. "The Republicans Should Pray for Rain: Weather, Turnout, and Voting in U.S. Presidential Elections." Journal of Politics 69(3):649-663.

Hansford, Thomas G. and Brad T. Gomez. 2010. "Estimating the Electoral Effects of Voter Turnout.” American Political Science Review 104(2):268-288.

Herrmann, Michael, Simon Munzert and Peter Selb. 2016. "Determining the effect of strategic voting on election results." Journal of the Royal Statistical Society Series A 179(2):583-605.

Hoeting, Jennifer A., David Madigan, Adrian E. Raftery and Chris T. Volinsky. 1999. “Bayesian Model Averaging: A Tutorial." Statistical Science 44:382-417.

Hooghe, Marc and Anna Kern. 2016. "The Tipping Point between Stability and Decline: Trends in Voter Turnout, 1950-1980-2012.” European Political Science pp. 1-18. 
Ipsos MORI. 2018. Likelihood of Voting. URL: https://www.ipsos.com/ipsos-mori/enuk/likelihood-voting.

Jackman, Robert W. 1987. "Political institutions and voter turnout in industrial democracies.” American Political Science Review 81:405-424.

John, Peter, Anthony Bertelli, Will Jennings and Shaun Bevan. 2013. Policy agendas in British politics. Basingstoke: Palgrave Macmillan.

Katosh, J. and M. Traugott. 1981. "The Consequences of Validated and Self-Reported Voting Measures.” Public Opinion Quarterly 45(4):519-535.

Katz, Daniel. 1941. "The Public Opinion Polls and the 1940 Election.” Public Opinion Quarterly 5(1):52-78.

King, Anthony, Robert J. Wybrow and Alec Gallup. 2001. British Political Opinion, 1937-2000: The Gallup Polls. London: Politico's Publishing.

Kostadinova, T. 2003. "Voter turnout dynamics in post-Communist Europe." European Journal of Political Research 42(6):741-759.

Leamer, Edward E. 1978. Specification Searches. New York: Wiley.

Lewis-Beck, Michael S. 1988. Economics and Elections: The Major Western Democracies. Ann Arbor: University of Michigan Press.

Lewis-Beck, Michael S. and Tom W. Rice. 1984. "Forecasting Presidential Elections: A Comparison of Naïve Models." Political Behavior 6(1): 9-21.

Lewis-Beck, Michael S. and Mary Stegmaier (eds.). 2014. "United States Presidential Elections Forecasting." PS: Political Science and Politics 47(2).

Linzer, Drew. 2013. "Dynamic Bayesian Forecasting of Presidential Elections in the States.” Journal of the American Statistical Association 108(201): 124-134.

Loewen, Peter John and André Blais. 2006. “Did Bill C-24 Affect Voter Turnout? Evidence from the 2000 and 2004 Elections.” Canadian Journal of Political Science 39(4):935-943.

Mellon, Jonathan, Geoffrey Evans, Edward A. Fieldhouse, Jane Green, and Christopher Prosser. 2018. “Aggregate Turnout Is Mismeasured.” Unpublished Manuscript. http://dx.doi.org/10.2139/ssrn.3098436

Miller, Mungo. 1952. “The Waugekan Study of Voter Turnout Prediction.” Public Opinion Quarterly 16(3):381-398.

Mortimore, Roger and Andrew Blick (eds.). 2018. Butler's British Political Facts. London: Palgrave Macmillan. 
Niemi, Richard G., Guy Whitten and Mark N. Franklin. 1992. "Constituency Characteristics, Individual Characteristics and Tactical Voting in the 1987 British General Election.” British Journal of Political Science 22:229-254.

Pacek, Alexander and Benjamin Radcliff. 1995. "Turnout and the Vote for Left-ofCentre Parties: A Cross-National Analysis.” British Journal of Political Science 25(1):137-143.

Pattie, C. J. and R. J. Johnston. 1998. "Voter turnout and constituency marginality: geography and rational choice." Area 30(1):38-48.

Pattie, C. J., R. J. Johnston and E. A. Fieldhouse. 1995. "Winning the local vote: the effectiveness of constituency campaign spending in Great Britain, 1983-1992." American Political Science Review 89:969-983.

Pattie, Charles and Ron Johnston. 2001. "A Low Turnout Landslide: Abstention at the British General Election of 1997." Political Studies 49(2):286-305.

Petrocik, John R. 1996. "Issue ownership in presidential elections, with a 1980 case study.” American journal of political science pp. 825-850.

Powell, G. Bingham. 1982. Comparative Democracies: Participation, Stability and Violence. Cambridge, MA: Harvard University Press.

R Core Team. 2017. R: A Language and Environment for Statistical Computing. Vienna, Austria: R Foundation for Statistical Computing. URL: https://www.Rproject.org/

Radcliff, Benjamin. 1994. "Turnout and the Democratic Vote." American Politics Research 22(3):259-276.

Raftery, Adrian E., Ian S. Painter and Chris T. Volinsky. 2005. "BMA: an R package for Bayesian model averaging." R News 5(2):2-8.

RePass, David E. 1971. "Issue Salience and Party Choice.” American Political Science Review 65(2):389-400.

Rosenstone, Steven. 1982. "Economic adversity and voter turnout." American Journal of Political Science 26(1):25-46.

Selb, Peter and Simon Munzert. 2013. "Voter overrepresentation, vote misreporting, and turnout bias in postelection surveys." Electoral Studies 32(1):186-196.

Vowles, Jack, Gabriel Katz and Daniel Stevens. 2017. "Electoral Competitiveness and Turnout in British Elections, 1964-2010.” Political Science Research and Methods 5(4):775-794.

Wells, Anthony. 2018. UK Polling Report. URL: http://ukpollingreport.co.uk/. 
Wlezien, Christopher, Will Jennings, Stephen Fisher, Robert Ford, and Mark Pickup.

2013. Polls and the Vote in Britain. Political Studies 61(S1): 129-154.

Zeugner, Stefan and Martin Feldkircher. 2015. "Bayesian Model Averaging Employing Fixed and Flexible Priors: The BMS Package for R.” Journal of Statistical Software 68(4):1-37. 


\section{ONLINE SUPPORTING INFORMATION}

Table S1: Root mean squared prediction error in (\%-points) using latest poll in months before the election

\begin{tabular}{rcccccccc}
\hline \multicolumn{1}{l}{ Predictor } & \multicolumn{10}{c}{ Month } \\
\cline { 2 - 9 } & 0 & 1 & 2 & 3 & 4 & 5 & 6 \\
\hline Likelihood-to-vote poll & & & & & & & \\
$1951-2017$ & NA & NA & NA & NA & NA & NA & NA \\
$1979-2017$ & 5.8 & 5.8 & 5.8 & 5.8 & 5.8 & 5.8 & 5.8 \\
Structural model & & & & & & & \\
$1951-2017$ & 5.0 & 5.6 & 5.9 & 5.5 & 5.3 & 6.0 & 6.8 \\
$1979-2017$ & 5.3 & 6.7 & 7.1 & 6.4 & 6.1 & 6.4 & 6.2 \\
Both combined & & & & & & & \\
$1951-2017$ & 4.5 & 4.4 & 4.7 & 4.4 & 4.5 & 5.0 & 6.0 \\
$1979-2017$ & 4.3 & 4.8 & 5.2 & 4.7 & 4.7 & 4.7 & 4.5 \\
\hline
\end{tabular}

Table S2: Root mean squared prediction error in (\%-points) using average of polls in months before the election

\begin{tabular}{rcccccccc}
\hline \multicolumn{1}{l}{ Predictor } & \multicolumn{10}{c}{ Months } \\
\cline { 2 - 8 } & $0-1$ & $1-2$ & $2-3$ & $3-4$ & $4-5$ & $5-6$ & $6-7$ \\
\hline Likelihood-to-vote poll & & & & & & & \\
$1951-2017$ & NA & NA & NA & NA & NA & NA & NA \\
$1979-2017$ & 5.8 & 5.8 & 5.8 & 5.8 & 5.8 & 5.8 & 5.8 \\
Structural model & & & & & & & \\
$1951-2017$ & 5.4 & 5.5 & 5.7 & 5.7 & 5.5 & 5.8 & 6.5 \\
$1979-2017$ & 6.0 & 6.2 & 6.3 & 6.4 & 5.6 & 6.1 & 6.2 \\
Both combined & & & & & & & \\
$1951-2017$ & 4.6 & 4.6 & 4.7 & 4.8 & 5.0 & 4.9 & 5.7 \\
$1979-2017$ & 4.8 & 4.6 & 4.7 & 4.9 & 4.7 & 4.7 & 4.7 \\
\hline
\end{tabular}

